\begin{abstract}
¿Cómo citar este artículo?
Mondragón Duarte, S. L., Guzmán Quintero, A. y Pérez Medina, A. G. (enero-abril, 2020). Regulación del tratamiento penitenciario y carcelario en el marco de los derechos humanos. Revista Virtual Universidad Católica del Norte, (59), 166-187 doi: https://doi.org/10.35575/rvucn.n59a10
\end{abstract}

\title{
Regulación del tratamiento penitenciario y carcelario en el marco de los derechos humanos
}

\section{Regulation of penitentiary and prison treatment within the framework of human rights}

\author{
Sergio Luis Mondragón Duarte \\ Magister en Derecho Público \\ Universidad Cooperativa de Colombia \\ Colombia \\ sergio.mondragon@ucc.edu.co \\ Orcid: https:/ /orcid.org/0000-0002-5189-6770
}

\author{
Aldemar Guzmán Quintero \\ Magíster en Derecho de Familia \\ Universidad Cooperativa de Colombia \\ Colombia \\ aldemar.guzman@campusucc.edu.co \\ Orcid: https: / /orcid.org/0000-0003-1832-9325
}

\section{Andrés Gustavo Pérez Medina \\ Especialista en Derecho de Daños, Responsabilidad Pública y Privada. Universidad Cooperativa de Colombia Colombia andres.perezme@campusucc.edu.co Orcid: https:/ /orcid.org/0000-0002-5318-7986}

Recibido: 12 de junio de 2019 Evaluado: 30 de septiembre de 2019 Aprobado: 10 de diciembre Tipo de artículo: Reflexión de 2019

\section{Resumen}

El presente artículo expone la regulación actual del régimen penitenciario y carcelario en el marco de los derechos humanos, dado que es menester destacar la importancia que tienen las entidades e instituciones públicas y privadas, vinculadas o asociadas a esta función, en el reconocimiento de garantías, salvaguarda de derechos, otorgamiento de beneficios intra o extramurales, así como en la rehabilitación, reinserción y restablecimiento de derechos del sujeto privado de la libertad. Por tal motivo, el objetivo de este opúsculo radica en mostrar la perspectiva actual del sistema penitenciario y carcelario en Colombia, a partir del método hermenéutico, mediante el cual se logra interpretar la aplicación de instrumentos internacionales que existen en materia de derechos humanos, como la Convención Americana de Derechos Humanos; establecer su relación con las políticas de protección y resocialización de las personas privadas de la libertad en establecimientos penitenciarios y carcelarios del país; y ofrecer, como resultado final, la implementación de estos postulados en el nuevo esquema del derecho penitenciario, centrado en la construcción de un proyecto de vida para el penado, por medio de recursos personales, el apoyo familiar y el acercamiento efectivo de las entidades e instituciones intervinientes, tendientes a lograr su resocialización plena.

Palabras clave: Derechos humanos, Establecimientos penitenciarios y carcelarios, Política prevencionista, Resocialización de la pena, Tratamiento de internos. 


\section{| Abstract}

This article describes the current regulation of the prison and prison system in the framework of human rights, given that it is necessary to highlight the importance of public and private entities and institutions, linked or associated with this function, in the recognition of guarantees, safeguarding of rights, granting of intra or extramural benefits, as well as rehabilitation reintegration, and restoration of rights of the person deprived of liberty. For this reason, the objective of this paper is to show the current perspective of the prison and prison system in Colombia, based on the hermeneutic method, through which it is possible to interpret the application of international instruments that exist in the field of Human Rights, such as American Convention on Human Rights; establish its relationship with the policies of protection and resocialization of persons deprived of liberty in prisons and prisons in the country; and offer as a final result, the implementation of these postulates in the new prison law scheme, focused on the construction of a life project for the prisoner, through personal resources, family support and the effective approach of entities and institutions intervening, tending to achieve full resocialization.

Palabras clave: Human Rights, Penitentiary and prison establishments, Prevention policy, Resocialization of punishment, Internal treatment.

\section{| Introducción}

La reclusión al interior de establecimientos penitenciarios y carcelarios comporta la garantía y protección de derechos humanos, como la dignidad humana, los cuales han sido reconocidos por ordenamientos jurídicos en el ámbito nacional e internacional. En ese sentido, en Colombia la evolución del régimen penitenciario y carcelario se ha dado con ocasión del cambio de finalidad de la pena, que pasó del correccionalismo a la resocialización (Acosta, 1996).

Lo anterior, se configuró a partir de la necesidad de ajustar la estructura legislativa, reguladora de esta materia en Colombia, a los postulados sobre reconocimiento, respeto y salvaguarda de los derechos humanos, contenidos en la Convención Americana de los Derechos Humanos, depositada por la Organización de los Estados Americanos, luego de su adopción en San José de Costa Rica en el 22 de noviembre de 1969 (Secretaría General de la Organización de Estados Americanos, 1978).

De esta manera, la nueva legislación penitenciaria en Colombia consagra taxativamente el respeto por la dignidad humana (Huertas, Trujillo y Silvera, 2015), previendo que cada centro de acumulación garantice la observancia estricta de los derecho universales (Quintero, 2011), para evitar cualquier trato violatorio de los bienes protegidos del penado, por medio de la aplicación de las reglas de proporcionalidad y necesidad, en obediencia a los instrumentos para el cumplimiento de la pena, la cual debe estar libre de cualquier violencia física, moral o síquica (López, 2017).

Esta legislación viene acompañada de políticas de igualdad y enfoque diferencial (Del Pozo y Martínez, 2015) que protegen al sujeto carcelario de cualquier manifestación de discriminación, en virtud de nacionalidad, raza, creencias, sexualidad, situación de discapacidad o ideología; 
esto, sumado a procesos terapéuticos de trabajo, estudio y enseñanza, serán de gran utilidad para la obtención de beneficios administrativos y judiciales que permitan redimir la pena en menos tiempo (Ley 65, 1993; Ley 1709, 2014).

Lo anterior, ha llevado a que las reformas en la legislación y en la reglamentación penitenciaria y carcelaria hayan obedecido a la necesidad de acentuar la aplicación de los mecanismos de custodia, vigilancia, resocialización y reintegración social frente a las personas privadas de la libertad, por parte del Estado (Núñez, 2017), para garantizar la permanencia incólume del recluido, lo cual sin perjuicio de su normal deterioro por el paso del tiempo, obliga a ser devuelto a la sociedad en mejores condiciones fisicas, psicológicas y mentales a las que fue condenado, con la anuencia e inversión efectiva de "recursos humanos y materiales, investigación científica y social y, sobre todo, humanidad" (González, 2010), al interior de los establecimientos penitenciarios y carcelarios.

Con todo, el artículo de investigación presenta como estructura, en primer lugar, la indicación del marco teórico utilizado para el desarrollo de las categorías presentadas; en segundo lugar, el abordaje de la metodología empleada para el estudio del tema propuesto; en tercer lugar, la presentación de los resultados, enmarcados en cuatro capítulos, que van desde la reclusión al interior de establecimientos penitenciarios y carcelarios hasta el paradigma penitenciario y carcelario, de cara a los derechos humanos, bajo la Constitución Política de 1991; y, por último, la relación de las conclusiones finales que arrojó la investigación.

\section{| Marco teórico}

El concepto de pena en Colombia no va dirigido solamente a la reparación del daño ocasionado por delincuentes, sino a la prevención de su ocurrencia y a la protección del condenado, de tal manera que se le prevenga a la sociedad de la comisión de conductas delictivas, y también se garantice la resocialización, reincorporación y reintegración social del privado de la libertad (Ríos, 2016).

De esta manera, la resocialización se concibió, en continentes como Europa, a partir de la década de los cincuenta y sesenta, cuando se entendió que el castigo debía "procurarse con medidas de defensa preventivas, educativas y curativas, en lugar de con penas" (Adelantado, 1993). Sin embargo, en Colombia el concepto de resocialización se incorporó con la Ley 65 de 1993, en la medida que "el tratamiento penitenciario se asocia con el objetivo de la resocialización"(Ruiz-Pérez, Malaver-Pérez, Romero, López y Silva, 2018), dado que la resocialización al interior del tratamiento penitenciario colombiano es en sí mismo un tratamiento posterior a la sentencia condenatoria, en materia penal, que le permitirá al recluido retornar a la sociedad con conocimiento de la equivocación cometida, con conciencia del respeto de las normas sociales y con predisposición de volver a incurrir en un delito a futuro (Hernández, 2018).

Teniendo en cuenta lo anterior, “la resocialización y la humanización de la pena deben cumplir con los fundamentos morales de las normas del tratamiento penitenciario y carcelario" 
(Pedraza, 2015), toda vez que la función principal de la pena privativa de la libertad "es finalmente la resocialización y rehabilitación de aquellas personas que se encuentran en esta situación" (Mayorga, 2015, p. 4), la cual en caso de no darse podría constituir una violación a los derechos humanos (Mayorga, 2015).

En consonancia, son múltiples los autores e instituciones del derecho que reconocen que la resocialización es el fin fundamental de la función protectora y preventiva de la pena (Instituto Rosarista de Acción Social Rafael Arenas Ángel, 2011), la cual es direccionada por el Consejo Superior de Política Criminal, creado bajo el Decreto 2062 de 1995, como un órgano asesor a la Presidencia de la República, encargado de la formulación de la política criminal del Estado, que incorpora las herramientas de protección a la sociedad, prevención y represión del delito, resocialización del delincuente y evaluación de conflictos del sistema jurídico penal (Instituto Rosarista de Acción Social Rafael Arenas Ángel, 2011).

\section{| Metodología}

El presente es un artículo derivado de la investigación titulada "La ejecución de la política de la prevención del delito en el Estado colombiano", la cual se realizó desde un enfoque cualitativo, centrado en el método hermenéutico, para evidenciar cómo la evolución del Sistema Penitenciario en Colombia ha configurado mayores garantías de los derechos humanos de los individuos privados de la libertad, a partir de la implementación de principios fundamentales, dentro de un nuevo paradigma del derecho penitenciario, que permite la construcción de un proyecto de vida para el recluso, basado en recursos institucionales y personales, tendientes a la obtención de su resocialización efectiva.

En ese sentido, el carácter cualitativo de la investigación se argumenta en la acción indagatoria que busca una relación entre los hechos objeto de estudio y su interpretación (Sampieri, Fernández y Baptista, 2014); así mismo, es oportuno señalar lo mencionado por Ackerman y Com (2013), en tanto frente al método cualitativo expresan: "El enfoque cualitativo trabaja fuertemente ligado al contexto en donde se ubica el objeto de investigación y busca establecer relaciones entre ese marco contextual y el fenómeno a estudiar" (p. 41), de tal forma que este enfoque se base en observaciones y descripciones del tema planteado.

A su vez, la aplicación del método hermenéutico encuentra su fundamentación en autores como J. Giraldo y O. Giraldo (2007), quienes refieren la interpretación normativa aplicada en estos casos hacia lo sociológico, como el "significado de los términos de una norma adherido a la realidad social que expresa, y que en consecuencia conceptos tales como familia, trabajador o comerciante apuntan a elementos de la estructura social, y no a entelequias conceptuales abstractas" (p. 166); sin embargo, no se puede perder de vista cómo el objeto de la investigación jurídica termina afincándose, como indican Baquero y Gil (2015) en los hechos, los valores y las normas, aun cuando estos elementos no pueden ser contemplados de forma estática, sino que deben ser relacionadas con el tiempo, el espacio y la realidad social; por lo que en este caso, 
toda vez que la interpretación versa sobre el estudio de los derechos humanos, como categóricos normativos aplicables al tratamiento penitenciario y carcelario, se justifica la interpretación normativa vigente en la materia, con ocasión de la realidad que padecen las personas privadas de la libertad.

\section{| Resultados}

\section{La reclusión al interior de establecimientos penitenciarios y carcelarios}

Dentro del proceso histórico de la institución carcelaria, un primer estadio, como menciona Echeverry (1971), se traza desde el nacimiento de la Colonia, y termina con el triunfo de la campaña libertadora; un periodo marcado por un régimen con un trato cruel e inhumano de los reos, basado en un tratamiento que imponía la muerte, el destierro, el trabajo forzado y los castigos físicos, inspirados en la vindicta y el retribucionismo expiatorio, aplicados con instrumentos de disciplinamiento (Beccaria, 2010), por los soldados del ejército virreinal; estos fungieron como los primeros carceleros del sistema. Oscuridad superada en la época de la República por las buenas tareas del General Santander, quien suscitó la promulgación de la Ley de organización y régimen político y económico de los departamentos y provincias de la República, expedida el 11 de marzo de 1825, donde se establecieron las primeras disposiciones carcelarias (Echeverry, 1971; Howard, 2003).

Producto de los avances penológicos europeos que promovían la doctrina del correccionalismo (Melossi y Pavarini, 1980), se trae a la Republica una nueva idea de régimen carcelario y se ordena la creación de centros de reclusión en las capitales, suscitando el concepto de prisión como instrumento hegemónico del castigo de los criminales (Beytía, 2017). Lo anterior, motiva la primera legislación penitenciaria en 1838; régimen jurídico que se hizo ineficaz debido a los conflictos internos suscitados en las siguientes décadas del siglo XIX, generando la decadencia de la institución carcelaria; aun así, entre la primera legislación penitenciaria y la reivindicación de la institución carcelaria del siglo XX, se dictaron normas que regularon cuestiones operativas y administrativas, pero sin que se determinara una política sobre el trato y el tratamiento del penado, más allá de la idea del encerramiento con prácticas de disciplinamiento físico y moral, con el uso de nuevas arquitecturas para la acumulación humana (Foucault, 1983), adecuadas solo para la seguridad de la medida intramural, sin estrategias de educación, trabajo, atención médica y asesoría espiritual (Mercado, 2014).

\section{El cambio del paradigma penitenciario: del correccionalismo a la resocialización}

La institución carcelaria es revindicada hasta 1914 con la expedición de la Ley 35, norma que establece la clasificación de las penitenciarías, teniendo como criterio la duración de la condena, y regula la creación de la Dirección General de Prisiones y sus funciones administrativas y operativas; además, precisa como estructura fisica del sistema carcelario: las casas de presidio, las casas de prisión ${ }^{1}$ y las casas de reclusión ${ }^{2}$, y determina que los presos políticos no podrán ser recluidos en las penitenciarías, siendo el ejecutivo quien determine el lugar de su detención o prisión. Así, la norma vislumbra un tratamiento determinado por la edad, el tipo penal, la situación jurídica y la cuantía de la condena. 
El correccionalismo es superado por el paradigma de la resocialización, un saber penológico que se trasplanta al ordenamiento interno y reforma integramente el sistema penitenciario nacional, surgiendo en la vida jurídica las categorías penitenciarias: trato y tratamiento, lo que implica un régimen de intervención científica sobre el penado. En 1934 con el Decreto 1405, el Ejecutivo establece como base del tratamiento: la salubridad ${ }^{3}$, la atención médica ${ }^{4}$ y espiritual, la disciplina5, el trabajo y el estudio (Acosta, 1996).

Con respecto a la salubridad y a la atención médica y espiritual, se determinó que cada penado debía gozar de las condiciones necesarias para su salud física y mental, lo que sería reforzado con la atención directa de un cuerpo médico, quien procurarían que el personal interno estuviera en buenas condiciones de salud, y además se pudiera determinar las patologías criminales desde una perspectiva antropológica y sociológica. Trabajo reforzado por un capellán que alimentaría la moral de los privados con actos como: la misa, conferencias, asesoría personalizada y visitas a los enfermos y aislados por seguridad.

La disciplina se convierte en una herramienta de control, se ordena la creación de cuerpos colegiados, integrados por los profesionales que laboran en la misma cárcel, en cabeza del director, encargados de calificar y sancionar' las conductas de los internos, que son violatorias del reglamento de la cárcel. A los penados se les impone un régimen impositivo y prohibitivo que les determina todos los roles, mecanizando sus vidas, llevándolos a un proceso de sumisión y adoctrinamiento muy parecido a la vida castrense, que tiene por objeto hacerlos personas prosociales, trabajadoras y lejos de cualquier actividad delincuencial.

La doctrina carcelaria plantea que el trabajo y el estudio son la mejor terapia para la regeneración socio-moral; por tanto, en la cárcel el trabajo no es ordinario, sino terapéutico, y no es un derecho, sino una obligación. Por ello, los programas de promoción para el trabajo tenían ofertas variadas, como: trabajar en actividades agropecuarias en las granjas dentro de las mismas penitenciarias o en las colonias penales rurales, elaboración de artesanías en los patios y talleres internos de los centros carcelarios, y en algunos casos trabajar bajo el sistema de maquilas para empresas del sector de la industria, previos contratos celebrados con la

\footnotetext{
1 Era el lugar en donde se cumplian las penas de prisión o arresto, impuestas por el Poder Judicial, y donde se tenía en prisión preventiva a los sumariados y procesados con arreglo al Código de Procedimiento Judicial (Ley 35, 1914)

2 Era el lugar de encerramiento para: los menores de edad, los adultos con pena correccional impuesta por autoridad nacional y los hijos o pupilos rebeldes a quienes sus padres o tutores quieran colocar allí para su corrección. Dichos centros no tenían un carácter penal, sino de educación, pero con régimen muy severo (Ley 35, 1914)

${ }^{3}$ Se dispuso que los dormitorios de los penados tuvieran las condiciones necesarias para el aseo, higiene, aire, luz y espacio, que garantizarán el derecho de, por lo menos, cuatro metros cúbicos de aire en los dormitorios, espacios sin aglomeración, duchas suficientes para el baño diario y alimentos de calidad, cantidad y con las adecuadas condiciones de higiene y aseo (Decreto 1405, 1934, art. 16-19).

4 Se ordenó que todo centro carcelario tendría dos médicos, y uno debía ser especialista en antropología criminal, psicología experimental y psiquiatría; este estaría consagrado al estudio de la personalidad del delincuente, con fines de caracterizar la delincuencia y generar productos de investigación que tributaran al Comité Científico del Sistema Penitenciario (Decreto 1405 , 1934, art. 61-71).

$\mathbf{5}$ El régimen disciplinario imponía a los penados el obedecimiento irrestricto de las ordenes de los funcionarios, estaba prohibido los reclamos colectivos y juegos de azar, se imponía un régimen del silencio colectivo y de los horarios para levantarse y acostarse (Decreto 1405, 1934, art. 90-109).

6Dentro de las sanciones que imponía el comité de disciplina estaban la amonestación, el plantón, la pérdida de visitas, el aislamiento y la privación de: correspondencia, comprar comestibles, dormir en la cama, fumar, y de la mitad de la porción de comida (Decreto 1405, 1934, art. 181)
} 
administración de la cárcel y un estudio de las posibilidades de los internos, según su situación jurídica y sus conocimientos. Con respecto al estudio, se ordena la creación de escuelas en los centros carcelarios para superar el analfabetismo, bajo la presunción de que la ignorancia hace parte de la etiología del delito; también, se pretendió hacer educación moral y cívica sobre los penados, con herramientas como las conferencias de expertos y la construcción de bibliotecas, ordenando que la lectura de textos sobre temas morales fuera obligatoria.

La reforma penitenciaria de 1914 da lugar a la creación de la Dirección de Prisiones, decisión que marca el inicio del penitenciarismo en Colombia, el cual se sustenta epistemológicamente en el paradigma de la resocialización, entendido como la intervención científica de las personas en conflicto con la ley penal. Marco teórico que se concreta en la reforma hecha en 1934 con el Decreto 1405, norma que ordena que el trato y tratamiento del penado goce del principio de legalidad y se haga en el marco de las actividades terapéuticas del trabajo, estudio, salud, disciplina y asesoría espiritual, las cuales son la base para la trasformación del criminal. Aunque en la voz de tratadistas penitenciarios se concibe la reforma como una mera formalidad (Echeverry, 1971), pues la realidad fue otra debido al poder discrecional que les fue otorgado a los directores de las cárceles (Ruiz, 2007).

En 1960, con el Decreto 1716, se impone al Ministerio de Justicia, entre otras cosas, afianzar las políticas para el trato y tratamiento de los penados, que incluyan las regulaciones necesarias para garantizar la salud, la alimentación, la rehabilitación, la educación y las demás actividades pertinentes para la resocialización. En 1964, con el Decreto 1817, se reforma el régimen penitenciario establecido en el Decreto 1405 de 1934, adicionándose las actualizaciones de lineamientos de normas internacionales en derechos humanos para los privados de la libertad, a partir de una clasificación científica de los penados ${ }^{7}$ y de los establecimientos carcelarios ${ }^{8}$, la actualización de los servicios de salud y educación, el mejoramiento de las condiciones de trabajo intracarcelario y la eliminación de sanciones que atentaban contra la dignidad humana.

La reforma de 1964, con el Decreto 1817, sin duda alguna actualizó el Sistema Penitenciario y configuró el respeto por los derechos humanos de los privados de la libertad; aun así, evidenciaba algunas normas que creaban un déficit de la protección de los mismos, dado que el penado seguía siendo un sujeto pasivo de las relaciones penitenciarias y se cosificaba al tenerlo como objeto de intervención, bajo una configuración caducada de los marcos teóricos de la resocialización que se limitaba al estudio del penado, sin tener en cuenta la perspectiva del intervenido, conllevando al fracaso de los fines del sistema. Por ello, los tratadistas penitenciarios, luego de un largo trabajo, lograron la reforma del Sistema Penitenciario con la Ley 65 de 1993, reformada luego por la Ley 1709 de 2014, en donde se implementaron los principios de un nuevo paradigma del derecho penitenciario: el prevencionismo, basado en la construcción de un proyecto de vida a partir de los recursos personales y de la motivación del mismo penado, el cual es concluyente con los fines de la resocialización.

7Se ordenó la separación entre hombres y mujeres, menores y adultos, detenidos y condenados, debiendo clasificar a los reclusos en agrupaciones homogéneas, según la clase y modalidad el delito, condición sexual, reincidencia, grado de escolaridad, origen residencial, costumbres, modo de vida, aptitudes para el trabajo, estado de salud y antecedentes (Decreto 1817, 1964, art. 24-36).

$\mathbf{8}$ Los establecimientos carcelarios de clasificaron en a) Penitenciarías Rurales y Urbanas; b) Cárceles Distritales; c) Cárceles Municipales; d) Cárceles para militares; e) Colonias Agricolas, Industriales o Mixtas; f) Cárceles para Mujeres; g) Sanatorios Penales Antituberculosos; h) Manicomios Criminales; i) Anexos Siquiátricos; y j) Instituciones para protección de los post-penados (Decreto 1817, 1964, art. 5). 


\section{Trato y tratamiento penitenciario y carcelario en el marco de los derechos humanos}

Los derechos humanos han sido considerados, a lo largo de muchos años, como un conjunto de garantías mínimas, inherente a los seres humanos, por el solo hecho de serlo. En ese sentido, se tiene que estos derechos comprenden una gama de valores y principios, como la dignidad humana y el mínimo vital, que por su fuerte contenido axiológico han permitido moderar ciertas conductas excesivamente coercitivas, como las de violencia psicológica o agresión física, desplegadas al interior de los institutos penitenciarios y carcelarios (Oficina en Colombia del Alto Comisionado de las Naciones Unidas para los Derechos Humanos, 2006).

En relación con lo anterior, vale la pena destacar que a nivel del derecho internacional el tratamiento de reclusos, al interior de institutos penitenciarios y carcelarios, se ha visto regulado por medio de instrumentos jurídicos que permiten, a primera vista, garantizar la dignidad humana y el respeto por las garantías mínimas a la salud, el trabajo, el ocio, la familia, la religión y la cultura.

En ese orden de ideas, las reglas mínimas para el tratamiento de reclusos fueron acogidas por la Organización de las Naciones Unidades en el Primer Congreso sobre Prevención del Delito y Tratamiento del Delincuente, llevado a cabo en Ginebra en el año 1955. De esta manera, se adoptaron una serie de principios para la protección de personas recluidas o detenidas en establecimientos penitenciarios y carcelarios, cuyo revestimiento normativo propiamente dicho, se llevó a cabo en la Asamblea General de las Naciones Unidas en 1990. Estos principios a groso modo afirman que:

Todos los presos y detenidos deben ser tratados con respeto a su dignidad humana en relación con las condiciones de detención. Se ocupan de las siguientes cuestiones: trato y disciplina; contacto con el mundo exterior; salud; clasificación y separación; quejas; registros; trabajo y ocio, y religión y cultura. (Oficina del Alto Comisionado de las Naciones Unidas para los Derechos Humanos, 2004, pp. 15-16).

Estas disposiciones normativas son expedidas en el marco de un postulado categórico relevante para el derecho procesal y sustantivo, que es la dignidad humana, la cual comprende distintos derechos contenidos dentro de esquemas constitucionales, como son el derecho a la vida, el mínimo vital, la integridad personal, física, moral, espiritual y religiosa, el libre desarrollo a la personalidad, las libertades de conciencia y de religión, la intimidad, el debido proceso, la salud, el trabajo y el adecuado tratamiento penitenciario, como garantía en sí mismas (Carreño, 2016).

Este concepto de la dignidad humana trajo consigo múltiples cambios en la Constitución Política de Colombia de 1991, como se observará más adelante, a tal punto que reconoce la relación de sujeción especial que existe entre el Estado y el personal recluido al interior de los establecimientos penitenciarios y carcelarios, con fundamento en los ideales propugnados por el Estado Liberal, que a su vez genera una reciprocidad de deberes y derechos entre ambos, toda vez que la correlación de estas situaciones yace en la confrontación de la superioridad jerárquica con que cuenta la administración, como forma de institucionalización del ente estatal versus la garantía de permanencia incólume del recluido, que sin perjuicio del deterioro natural, por el paso del tiempo, merece ser devuelto a la sociedad en mejores condiciones fisicas, psicológicas 
y mentales a las que fue condenado, puesto que el carácter resocializador de la pena debe dar lugar al cumplimiento de este cometido (Ministerio de Justicia y del Derecho-Dirección de Política Criminal y Penitenciaria, 2017).

\section{El Sistema Penitenciario y Carcelario en el esquema de la Convención Americana de los Derechos Humanos}

El Sistema Interamericano de Derechos Humanos, mediante la Convención Americana de Derechos Humanos, estatuye en su articulado la defensa por la vida y la integridad personal en el marco de los sistemas penitenciarios y carcelarios; así, en su artículo 5 dispone:

Artículo 5. Derecho a la Integridad Personal.1. Toda persona tiene derecho a que se respete su integridad fisica, psiquica y moral. 2. Nadie debe ser sometido a torturas ni a penas o tratos crueles, inhumanos o degradantes. Toda persona privada de libertad será tratada con el respeto debido a la dignidad inherente al ser humano. 3. La pena no puede trascender de la persona del delincuente. 4. Los procesados deben estar separados de los condenados, salvo en circunstancias excepcionales, y serán sometidos a un tratamiento adecuado a su condición de personas no condenadas. 5. Cuando los menores puedan ser procesados, deben ser separados de los adultos y llevados ante tribunales especializados, con la mayor celeridad posible, para su tratamiento. 6. Las penas privativas de la libertad tendrán como finalidad esencial la reforma y la readaptación social de los condenados. (Secretaría General de la Organización de Estados Americanos, 1978).

De esta manera, puede notarse como la Convención Americana crea obligaciones para la defensa y garantía de los derechos humanos de los asociados de los Estados parte del Sistema Interamericano, incluyendo de forma directa a la población carcelaria como sujetos de especialísima importancia, dadas sus condiciones de sometimiento frente a los Estados en lo que respecta a su derecho a la libertad. De esta forma, estos derechos de la población reclusa se erigen con una doble connotación, respecto de las disposiciones normativas consagradas en la Convención Americana, y es que tendrán una configuración de derechos para los asociados, como a su vez una carga obligacional para el Estado, según puede observarse a continuación:

(...) el artículo 1(1) de la Convención establece claramente la obligación del Estado de respetar los derechos y libertades reconocidos en la Convención y de garantizar su libre y pleno ejercicio. La declaración Americana de los Derechos y Deberes del Hombre señala en su artículo XVIII el derecho de garantías judiciales para el amparo contra actos de la autoridad, e indica en su preámbulo que las instituciones jurídicas y políticas de los Estados tienen como finalidad principal la protección de los derechos humanos. Por consiguiente, estos preceptos de derecho internacional imponen al Estado el deber fundamental de respeto y garantía, de tal modo que toda violación de los derechos reconocidos en Declaración y en la Convención que puedan ser atribuidos, de acuerdo con las normas del derecho internacional, a acción u omisión de una autoridad pública, constituyen un acto de responsabilidad del Estado. (Duran, 2006, pp. 152-153). 
Ante la importancia que adquieren los derechos de los reclusos en el marco del Derecho Internacional de los Derechos Humanos, en este caso en el Sistema Interamericano, seguidamente se pasará a abordar algunos supuestos fácticos estudiados, tanto por la Corte Interamericana de Derechos Humanos en su facultad de decretar medidas cautelares para la garantía de los derechos convencionales, como también en sus facultades contenciosas. Teniendo como punto de vital importancia lo dicho por Castro (2018) así:

El grado de injerencia en la libertad y otros derechos fundamentales, como la vida e integridad corporal, explican la gran importancia de los controles y límites exigidos por la Corte. La política criminal imperante ha producido un complejo escenario para el funcionamiento de los sistemas penitenciarios, el cual pone en jaque la dignidad humana de los presos. Este escenario ha generado una serie de casos que han sido juzgados por la Corte y que le han permitido construir en el tiempo un conjunto de estándares en materia penitenciaria. No sería errado afirmar que estos estándares jurisprudenciales fijados por la Corte se han levantado como mínimos que los Estados deben respetar en el interior de sus jurisdicciones y como orientaciones que buscan racionalizar no solo la administración de las prisiones, sino el desconcertante discurso punitivo imperante en la región. (p. 51).

De cualquier manera, el Sistema Interamericano de Derechos Humanos ha adoptado estándares, en aras de garantizar los derechos consagrados en la Convención Americana de Derechos Humanos; con todo es importante resaltar:

Así, al momento en que el Estado sujeta a su custodia a una persona, toma control de ella, y por lo tanto sus obligaciones respecto de dicha persona se vuelven más rigurosas en varios sentidos. De un lado, es deber del Estado velar por la vida e integridad personal de las personas bajo su custodia, no solo por hechos cometidos por sus agentes, sino también por particulares (...) Si bien el Sistema Interamericano ha desarrollado estándares puntuales frente a las personas privadas de la libertad, lo ha hecho en la mayoría de las ocasiones para ampliar el contenido de derechos tales como el de la vida, la integridad personal o la libertad personal; sin embargo, hasta el momento estos estándares no se han relacionado -al menos no explícitamente-con su núcleo común: el deber de custodia. (Acosta y Amaya, 2011, pp. 322-323).

\section{| Casos de regulación específica para el tratamiento de internos en establecimientos penitenciarios y carcelarios}

\section{Resolución penitenciaria de Mendoza vs Argentina}

En el año 2004 la Comisión Interamericana de Derechos Humanos procede a estudiar la solicitud de medidas cautelares de los internos de las penitenciarías de Mendoza, Argentina; desde la cual se evidencian las graves condiciones de violencia al interior de los centros carcelarios que han desembocado en múltiples muertes de los internos, teniendo como eje graves problemas de saturación de reclusos, malas condiciones higiénicas y sanitarias, la falta de personal para el cuidado de los presos y, por último, el letargo de las soluciones que pudiesen 
garantizar los derechos de los reclusos.

Es como la Corte Interamericana, para la imposición de medidas cautelares, destaca la garantía de los derechos de los reclusos por parte del Estado argentino, mediante las obligaciones propias que impone el Sistema Interamericano de Derechos Humanos; de tal forma, el tribunal en aquella ocasión señala el deber que tienen los Estados parte de garantizar unas condiciones de dignidad mínimas para la población carcelaria, que permitan la garantía de sus derechos a la vida e integridad personal, ello en razón al especial grado de sujeción que tiene los penados respecto del Estado, por lo que este último termina cumpliendo una función de garante (Comisión Interamericana de Derechos Humanos, Resolución 22 de noviembre de 2004).

Sea entonces como la Corte destaque la posición de garante que tiene el Estado en la protección de la vida e integridad personal de los reclusos, aduciendo ya no solo obligaciones de abstenerse de causar daño por parte de sus autoridades, sino además evitando hechos lesivos que se pudiesen producir por los demás reos:

12. Que, para garantizar efectivamente los derechos consagrados en la Convención Americana, el Estado Parte tiene la obligación de proteger a todas las personas que se encuentren bajo su jurisdicción. Como lo ha dicho la Corte, tal obligación general se impone no sólo en relación con el poder del Estado sino también en relación con actuaciones de terceros particulares. En las circunstancias del presente caso, la Comisión alega que varias personas privadas de libertad han resultado muertas y heridas en riñas ocurridas entre internos. (Comisión Interamericana de Derechos Humanos, Resolución 22 de noviembre de 2004).

\section{Resolución complejo penitenciario Curado vs Brasil}

La Corte Interamericana de Derechos Humanos analiza la grave situación de vulneración de derechos humanos en el complejo penitenciario de Curado, en la provincia de Pernambuco, Brasil, en donde se aduce, como supuesto fáctico: el alegado empleo de prácticas disciplinarias y actos de violencia, como tortura, tratos crueles, inhumanos y degradantes; el uso excesivo de la fuerza por parte de los guardas, la falta de control efectivo, la falta de atención médica que posibilita la asunción de enfermedades contagiosas, el recrudecimiento de violencia por el hacinamiento que se presenta en la cárcel, la falta de alimentos y agua potable, y finalmente la falta de respuesta judicial efectiva. Así las cosas, la Corte Interamericana de Derechos Humanos encuentra una relación estrecha entre el marco descrito y la vulneración de los Derechos Humanos de los reclusos, lo cual a su vez desemboca en el incumplimiento del Estado de sus deberes convencionales.

Así, entonces, el tribunal hace énfasis en algunas circunstancias que pudiese afectar los derechos de la población penada como: 
(...) evitar la presencia de armas dentro de los establecimientos en poder de los internos, reducir el hacinamiento, procurar las condiciones de detención mínimas compatibles con su dignidad, y proveer personal capacitado y en número suficiente para asegurar el adecuado y efectivo control, custodia y vigilancia del centro penitenciario. (Corte Interamericana de Derechos Humanos, Resolución 22 de mayo de 2014).

Además de lo anterior, el Estado deberá repeler cualquier acto de violencia en contra de quienes se encuentran privados de la libertad, para así garantizar los derechos de esta población.

Así las cosas, en el presente caso la Corte Interamericana de Derechos Humanos decida decretar las respectivas medidas cautelares para la protección de los derechos convencionales a la vida y la integridad personal de las personas privadas de la libertad en el complejo penitenciario de Curado.

\section{Sentencia Walter Bulacio vs Argentina}

En este caso, Walter Bulacio, menor de edad, fue detenido por el respectivo comisario de la zona cuando se encontraba en un concierto; acto seguido de ser detenido y privado de la libertad, fue gravemente golpeado por las autoridades públicas, lo que terminaría en su posterior muerte. Así, el comisario sería investigado e imputado por varios delitos debido a su accionar en contra de Bulacio, pero todo ello sin frutos, por lo cual el presunto autor del crimen fue puesto en libertad (Corte interamericana de Derechos Humanos, Sentencia del 18 de septiembre de 2003).

Ante las diferentes recomendaciones hechas por la Comisión Interamericana de Derechos Humanos, que no fueron acatadas por la República Argentina, se presenta demanda ante la Corte Interamericana de Derechos Humanos, la cual frente al caso particular señala la obligación que tienen los Estados de garantizar los derechos de quienes son privados de la libertad, de cara a la Convención Americana; de alli que en este caso expone:

La Corte ha establecido que el Estado, como responsable de los establecimientos de detención, es el garante de estos derechos de los detenidos, lo cual implica, entre otras cosas, que le corresponde explicar lo que suceda a las personas que se encuentran bajo su custodia. Las autoridades estatales ejercen un control total sobre la persona que se encuentra sujeta a su custodia. La forma en que se trata a un detenido debe estar sujeta al escrutinio más estricto, tomando en cuenta la especial vulnerabilidad de aquél, función estatal de garantía que reviste de particular importancia cuando el detenido es un menor de edad. Esta circunstancia obliga al Estado a ejercer su función de garante adaptando todos los cuidados que reclama la debilidad, el desconocimiento y la indefensión que presentan naturalmente, en tales circunstancias, los menores de edad. (Corte Interamericana de Derechos Humanos, Sentencia del 18 de septiembre de 2003). 
Ante la flagrante vulneración de los derechos a la vida e integridad personal del menor Bulacio, en el marco de los derechos humanos, la Corte Interamericana decide, en primer lugar, ordenar al Estado argentino proseguir y concluir la investigación de los hechos del caso, como sancionar a los responsables del mismo; en segundo lugar, ordena al Estado argentino adecuar su normatividad interna al Sistema Interamericano, para con ello cumplir garantías de no repetición; y, finalmente, en virtud de la obligación de reparar de los Estados, parte consagrada en el Artículo 63.1 de la Convención Americana, condena al Estado argentino al pago de perjuicios de carácter material e inmaterial.

Del anterior precedente jurisprudencial puede destacarse cómo para el Sistema Interamericano de Derechos Humanos existe una obligación de parte de los Estados por la garantía de los derechos de los reclusos, debido a dos argumentos: en primera instancia, debido al fehaciente estado de indefensión en que se encuentran los reclusos, por la privación misma de la libertad; y en segundo lugar, por la posición de garante que ostenta el Estado en la guarda, garantía y protección de los derechos de la población carcelaria.

\section{Caso Mendoza y otros vs Argentina}

Cesar Mendoza, Claudio Núñez, Lucas Mendoza, Saúl Roldan y Ricardo Videla, fueron condenados a cadena perpetua siendo menores de edad por una disposición legal vigente en época de la dictadura argentina. De esta manera, como consecuencia de la privación de la libertad, los reos sufren diferentes daños en su integridad. Así, Lucas Mendoza sufre pérdida de la visión, se presenta la muerte de Ricardo Videla, se presentan lesiones a Lucas Mendoza y Saúl Roldan (Raso y Leone, 2016).

Ante las denuncias presentadas por las víctimas, el fiscal del caso decide archivar la investigación por cuanto en las querellas no se identificaron a los perpetradores de los hechos; es como la Corte Interamericana de Derechos Humanos procede al estudio frente al caso en concreto de la vulneración de los derechos convencionales de parte del Estado argentino, aduciendo una vez más el especial deber del Estado en la protección de los derechos de la población carcelaria, haciendo hincapié en el especial estado de sujeción que tienen los penados, dada la imposibilidad de estos de satisfacer sus necesidades por su propia cuenta y la garantía de su derecho a la salud:

Esta Corte ha establecido que el Estado tiene el deber, como garante de la salud de las personas bajo su custodia, de proporcionar a los detenidos revisión médica regular y atención y tratamiento médicos adecuados cuando asi se requiera. Al respecto, la Corte recuerda que numerosas decisiones de organismos internacionales invocan las reglas mínimas para el tratamiento de los reclusos a fin de interpretar el contenido del derecho de las personas privadas de la libertad a un trato digno y humano. (Corte Interamericana de Derechos Humanos, Sentencia del 14 de mayo de 2013) 
Una vez configurada la vulneración de los derechos humanos de los demandantes, dado el especial deber del Estado en la garantía de sus derechos como sujetos de especial protección, al encontrarse privados de la libertad y cuya privación se dio siendo estos menores de edad, la Corte Interamericana decide ordenar medidas de rehabilitación, reparación y garantías de no repetición. Esto sin lugar a dudas genera una perspectiva diferente de modelos de reparación disimiles a los meramente económicos, partiendo del principio de reparación integral; con todo:

También resulta interesante, en lo que a privados de libertad se refiere, analizar las «otras formas de reparación» que en conjunto con las indemnizaciones buscan mejorar la posición de las víctimas o sus familiares, enviar mensajes de corte preventivo general y promover la modernización del sistema penitenciario. El tratamiento sicológico o la entrega de becas de estudios son otras medidas que la Corte ha considerado como formas de reparación que buscan brindar un apoyo adicional para las víctimas. También la obligación de investigar o de entregar el cuerpo a sus familiares son medidas reparadoras que apuntan a mejorar aún más la disminuida posición de los lesionados frente al Estado. (Castro, 2018, p. 50).

Por último, en el caso colombiano el Sistema Interamericano de Derechos Humanos, mediante la Comisión Interamericana de Derechos Humanos, ha detectado diversas situaciones que vulneran los derechos de la población carcelaria colombiana; como principales problemas se encuentran: superpoblación carcelaria y hacinamiento, normas relacionadas con detención preventiva y la libertad provisional y condicional, reclusión conjunta de procesados y condenados, deficiencia en servicios de salud y otros programas destinados a los internos, alimentación inadecuada y vulneración de los derechos de los reos a mantener vínculos de familiaridad (Comisión Interamericana de Derechos Humanos, 1997). Lo anterior se ha visto reflejado en condenas patrimoniales al Estado colombiano por parte del máximo tribunal de la jurisdicción de lo contencioso administrativo, en donde resulta de importancia destacar como a prima facie la jurisprudencia del Consejo de Estado utiliza el régimen de imputación objetiva como título jurídico para justificar la condena, pero aclarando que no siempre se rige bajo ese título:

La jurisprudencia de lo contencioso administrativo ha sostenido que el título de imputación aplicable a los perjuicios que se lleguen a causar a las personas privadas de la libertad es de naturaleza objetiva; es preciso resaltar que en algunos casos, el título de imputación aplicable a los daños sufridos por los reclusos, derivados de la prestación del servicio de salud por parte del establecimiento carcelario será de naturaleza subjetiva sustentado en la falla del servicio, sustentado en la aplicación de los servicios prestados a las personas privadas de la libertad como sujetos que se encuentran en situación particular, en las mismas condiciones de calidad, oportunidad, eficacia y eficiencia de las que no lo están, en virtud de las relaciones de especial sujeción con el Estado. (Jara, 2017, p. 101).

Por lo anterior, el concepto de justicia correctiva surge como eje imbricador y argumentativo para estatuir la responsabilidad del Estado por daños ocasionados, producto del servicio penitenciario y carcelario; sobre este aspecto filosófico Fabra (2015): 
El argumento a favor de la responsabilidad subjetiva de un argumento exegético adicional. En todo caso, la noción central es que el equilibrio entre las partes no se vulnera por la simple causación fáctica de un perjuicio, sino que su rompimiento requiere una vulneración normativa solo se vulnera el equilibrio cuando las personas actúan de una forma que no están legitimadas, es decir, por fuera de sus derechos y violando los deberes que tiene frente a los demás. La vulneración implica que hay pérdidas y ganancias normativas correlativas entre el dañador y la víctima: cuando a una víctima se le viola un derecho y con ello sufre una pérdida normativa, esta es a su vez es correlativa a una ganancia normativa del dañador. De esta concepción del "equilibrio normativo" se deriva el argumento que sostiene que la culpa es el único modelo coherente con la justicia correctiva, debido a que únicamente el incumplimiento de los deberes genera responsabilidad extracontractual, se requiere que la actuación del demandado sea ilícita, es decir, que haya vulnerado el estándar relevante ("hombre razonable", "buena padre de familia", etc.). (p. 2565).

Con todo es que Jara (2017), sobre Mosset (2004), mencione cómo el sistema de imputación subjetiva implica un reproche a la administración y al servidor público:

(...) la reparación no debe entenderse tan solo como obligación sino también como sanción en la medida que busca castigar a la persona que le ha causado daño a otra, que ha incumplido con una norma, con el fin de que situaciones como estas no se repitan (...) De cualquier manera se puede establecer que en la responsabilidad por daños ocasionados a los reclusos en los centros penitenciarios y carcelarios se encuentra en medio de los dos títulos de imputación, daño especial y falla en el servicio, dependiendo de que se acredite un defecto o error en el cumplimiento de los deberes del personal de custodia. ( $p$. 83).

Estas situaciones ofrecen especial trascendencia en materia de responsabilidad del Estado en Colombia por daños ocasionados a la población carcelaria, dadas las flagrantes vulneraciones de derechos humanos, en razón de la similitud argumentativa usada por el Consejo de Estado con la Corte Interamericana de Derechos Humanos para la declaratoria de responsabilidad.

\section{| El paradigma penitenciario y carcelario de cara a los derechos humanos bajo la Constitución Política de 1991}

La Carta Política de 1991 configuró una variación del paradigma penitenciario; la resocialización dejó de ser un asunto meramente científico y agregó un componente dogmático al derecho penitenciario, el cual establece la dignidad humana como episteme jurídica, sustentado en principios y valores orientadores del trato y tratamiento que reciben los penados. La resocialización se amplió en su definición, y por tanto debe ser entendida desde los procesos de: rehabilitación, reinserción, restablecimiento y otros estados positivos del sujeto privado de la libertad.

De esta manera, se destaca el respeto por el principio de la dignidad humana (Huertas et al., 
2015), al interior de cada uno de los centros penitenciarios y carcelarios, pues a partir del mismo se inspira, promueve y garantiza la salvaguarda de los demás derechos universales (Quintero, 2011) que configuran la protección a los bienes del penado, así como el inexorable cumplimiento de reglas de proporcionalidad en la aplicación de instrumentos, tendientes a la redención de pena, libres de cualquier tipo de violencia física, moral o síquica (López, 2017).

Ante las políticas de Estado para el reconocimiento de las minorías y de los grupos vulnerables; categorías donde se ubican los privados de la libertad, y por la naturaleza criminógena de la prisión, una arquitectura con espacios oscuros y soterrados, en la cual se guarda una privacidad desmedida, que incrementa la discrecionalidad de las relaciones de poder de los custodios y administradores de los centros penitenciarios, en detrimento de los privados, era pertinente que la norma precisara el trato intracarcelario, en términos de igualdad y enfoque diferencial (Del Pozo y Martínez, 2015), protegiendo al sujeto carcelario de cualquier manifestación de discriminación, en virtud de: nacionalidad, raza, creencias, sexualidad, situación de discapacidad o ideología.

La legislación penitenciaria actual trae a colación agregados a la pena resocializadora, entre ellos la función protectora y preventiva, a través de una formación integral que involucra componentes de disciplina, espiritualidad, visitas familiares, cultura, deporte, recreación y salud; todo lo anterior, sumado a procesos terapéuticos de trabajo, estudio y enseñanza, los cuales servirán para la redención de la pena, en términos de tiempo, con fines a acceder a beneficios administrativos y judiciales.

El trabajo penitenciario tiene una naturaleza terapéutica, lo cual no puede considerarse como trabajo ordinario, respecto del cual recae el régimen laboral, sino que está dirigido estrictamente a la resocialización del penado, por lo que las actividades están en el marco del respeto por los derechos humanos, dentro de lo cual se tiene que la oferta aplica para el privado de la libertad bajo criterios de: conocimiento, capacidad, edad y aptitud. Además, si en el proceso se generan productos comerciables con utilidad, se participa a título de bonificaciones a quienes intervinieron, como también se indica que el juez de penas concederá una redención de la pena en proporción de un día de reclusión por cada dos que trabaje, previa certificación de la Dirección del centro carcelario.

La educación y la enseñanza son ejes principales de la política de resocialización de los penados (Díaz, 2017; Ruiz, 2007); la nueva legislación ordena que al interior de los centros carcelarios se organice la estructura física que permita ofertar los diferentes niveles de enseñanza, previo cumplimiento de las formalidades exigidas por el Ministerio de Educación, que deben ir desde la alfabetización hasta programas universitarios. Para el cumplimiento de la política se tramitarán convenios con las secretarías de educación de los entes territoriales y con las universidades públicas, quienes apoyarán el proceso bajo las exigencias de la educación formal, con fines a que se otorguen títulos con la idoneidad exigida en el mercado laboral nacional, regional y local. 
En el transcurso de las diferentes actividades de la vida intracarcelaria, se van estableciendo unas etapas que preparan al penado para su vida en libertad (Gorra, 2013), enmarcadas dentro de un tratamiento de orden científico ${ }^{9}$ que verifica las condiciones psicosociales del reo, en el marco del respeto por la dignidad humana, la personalidad del penado y los cambios de la conducta criminal (Acosta, 2007). Dicho estudio es individual, progresivo e individualizado, y es trazado en unas fases progresivas que van desde la observación, el diagnóstico, los niveles de seguridad, hasta alcanzar la confianza para que le sea otorgado un beneficio administrativo ${ }^{10} \mathrm{O}$ su libertad.

La legislación penitenciaria colombiana se actualizó con las políticas nacionales e internacionales, en materia de los derechos humanos, aun así la Corte Constitucional precisó que los privados de la libertad se encuentran en condiciones de vulneración (Arenas y Cerezo Domínguez, 2016), y por ello los ubicó bajo la figura del Estado de cosas inconstitucionales; una realidad que es pertinente verificar, con fines a establecer el estado de los derechos humanos de los privados de la libertad en Colombia.

Un ejemplo claro de ello es el Decreto 040 del 12 de enero de 2017, que hace una adición a la reglamentación de los Centros Especiales de Reclusión, y en virtual del cual se tiene en cuenta el respeto por los derechos fundamentales de los reclusos con enfoque diferencial; dispone y ordena la prestación adecuada y oportuna de servicios de salud, higiene, alimentación, alojamiento, recreación y deporte, en condiciones de infraestructura óptimas; y previene la adaptación de lugares de reclusión para personas en condiciones de discapacidad, como ocurre en casos de condenados que padecen de trastorno mental. Con todo, la fórmula de del Estado social de derecho juega un papel de vital importancia dentro del sistema penitenciario y carcelario colombiano, en tanto que como menciona Palacios (2016) la pena no contempla una finalidad eminentemente retributiva, sino que deberá consultar criterios de proporcionalidad y necesariedad, con el objetivo de lograr la resocialización del penado, para así permitir un verdadero cambio en su interacción social.

Lo anterior, ha sido avalado por distintos estudiosos del derecho (Galvis, 2003) y de la gestión del desarrollo social (Micachán y Álvarez Rojas, 2018), quienes aseguran que la reinserción social se debe dar por medio de la resocialización, a través de tres puntos neurálgicos, propios de todo tratamiento penitenciario y carcelario, que son la salud, la educación y el trabajo (Galvis, 2003), aunados a los hábitos, valores y pautas de comportamiento, como la autodisciplina, la puntualidad, la responsabilidad, la valoración del esfuerzo y la convivencia, que se insertan e interiorizan en el individuo (Micachán y Álvarez, 2018), con el fin de dignificar su condición de persona recluida al interior del establecimiento penitenciario y carcelario.

\footnotetext{
'La evaluación científica de los privados de la libertad corresponde a un colegiado denominado Consejo de Evaluación y Tratamiento, conformado por grupos interdisciplinarios, donde participaran abogados, psiquiatras, psicólogos, pedagogos, trabajadores sociales, médicos, terapeutas, antropólogos, sociólogos, criminólogos, penitenciaristas y miembros del Cuerpo de Custodia y Vigilancia (Ley 65, 1993, art. 145).

$\mathbf{1 0}$ Los beneficios administrativos y judiciales que consagra la legislación penitenciaria son: permisos hasta de setenta y dos horas, la libertad y franquicia preparatorias; el trabajo extramuros y penitenciaría abierta harán parte del tratamiento penitenciario en sus distintas fases, de acuerdo con la reglamentación respectiva (Ley 65, 1993, art. 146).
} 


\section{| Conclusiones}

El Sistema Penitenciario y Carcelario en Colombia propugna actualmente por el respeto de los derechos humanos de los privados de la libertad, dado que, en virtud del Decreto 1817 de 1964, el penado seguía siendo un sujeto pasivo de las relaciones penitenciarias y se cosificaba al tenerlo como objeto de intervención, bajo una configuración caducada de los marcos teóricos de la resocialización, que se limitaba al estudio del penado, sin tener en cuenta la perspectiva del intervenido; lo cual conllevó al fracaso de los fines del sistema y, por ende, a la necesidad de interpretar las nuevas realidades normativas. De esta manera, se reinterpretó y modificó el paradigma penitenciario, que condujo hacia el prevencionismo y adoptó como finalidad la resocialización del penado.

No obstante, el Sistema Interamericano de Derechos Humanos, mediante la Comisión Interamericana de Derechos Humanos, ha detectado diversas dificultades que evidencian aún la vulneración de los derechos de la población carcelaria colombiana, como la superpoblación carcelaria y el hacinamiento, las normas relacionadas con detención preventiva y la libertad provisional y condicional, la reclusión conjunta de procesados y condenados, la deficiencia en servicios de salud, la alimentación inadecuada y vulneración de los derechos de los reos a mantener vínculos de familiaridad. En ese sentido, estas situaciones demandan especial atención en materia de la responsabilidad que le asistiría al Estado colombiano por daños ocasionados a la población carcelaria, dadas las flagrantes vulneraciones de derechos humanos, en razón de la similitud argumentativa usada por el Consejo de Estado con la Corte Interamericana de Derechos Humanos para la declaratoria de responsabilidad.

En relación con la política que comprende la función resocializadora de la pena, se aprecia la necesidad de garantizar el compromiso por las actividades que conllevan o implican la formación integral de los reclusos a través de los componentes internos del ser humano; por ello, es que los sistemas penitenciarios cada vez más deben buscar nuevas formas de redención del penado que permitan garantizar los fines propios de la pena, y además maximicen los derechos de esta población que, dado el contexto latinoamericano, terminan siendo una población vulnerable.

Igualmente, se ratifica que la educación y la enseñanza son los ejes principales de la política de resocialización de los penados, por lo que es importante que el Estado implemente políticas públicas, de la mano de los diferentes actores sociales, económicos y educativos, en aras de ofrecer una verdadera formación a quienes se encuentran privados de la libertad y con ello se supere, en muchas ocasiones, el nivel de marginalidad que ostenta esta población; además del factor inclusivo que este tipo de reformas podría generar, a nivel laboral, que garanticen una auténtica inserción del penado en la sociedad.

Por esta razón, desde la academia, las implicaciones prácticas de las investigaciones adelantadas en la materia, como la que se pone de presente, se orientan a propiciar en los establecimientos penitenciarios y carcelarios espacios de pensamiento y reflexión para los reclusos, acerca del valor que tiene la familia, el tiempo, el trabajo, la educación y la libertad, lo cual va de la mano con el valor agregado que ofrece el análisis de los textos, tendiente a la promoción, construcción y solidificación de relaciones afectivas agradables, estables o 
duraderas, y preferiblemente permanentes con otros reclusos, integrantes de su núcleo familiar y miembros del conglomerado social en general.

\section{Referencias}

Ackerman, S. y Com, S. (2013). Metodología de la investigación. Buenos Aires, Argentina: Aula taller.

Acosta, D. (1996). Sistema integral de tratamiento progresivo penitenciario. Bogotá, Colombia: E.P.N.

Acosta, D. (2007). Trato y tratamiento penitenciario. Bogotá, Colombia: Universidad Santo Tomás.

Acosta, J. y Amaya, A. (2011). La responsabilidad internacional del Estado frente al deber de custodia: estándares internacionales frente a los centros estatales de detención. Estudio socio-juridico, 13(2), 301-326.

Adelantado, J. (1993). De la resocialización a la nueva custodia. Teoría y práctica del tratamiento en Cataluña. Anuario de Derecho Penal y Ciencias Penales, (1), 199-222.

Arenas, L. y Cerezo Domínguez, A. (2016). Realidad penitenciaria en Colombia: la necesidad de una nueva política criminal. Revista Criminalidad, 58(2), 175-195.

Baquero, J. y Gil, E. (2015). Metodología de la investigación jurídica. Quito, Ecuador: Corporación de estudios y publicaciones.

Beccaria, C. (Trad. 2010). De los delitos y de las penas (3 ed.). Bogotá, Colombia: Editorial Temis.

Beytía, P. (2017). El panóptico de Bentham y la instrumentalización de los Derechos Humanos. Universitas Philosophica, 34(68), 173-196.

Castro, A. (2018). Estándares de la Corte Interamericana de derechos Humanos en materia de imputados y condenado privados de la libertad. Anuario de Derechos Humanos, (14), 35-54.

Carreño, J. M. (2016). Las cárceles como espacios de violación a los derechos humanos, estudio de caso: Cárcel Modelo de Bogotá (2002-2010). Bogotá, Colombia: Facultad de Ciencia Política, Gobierno y Relaciones Internacionales.

Comisión Interamericana de Derechos Humanos. (1997). Los derechos de las personas privadas de su libertad. Recuperado de http://www.cidh.oas.org/countryrep/Colom99sp/capitulo-14.htm

Congreso de la Republica de Colombia. (15 de octubre de 1914). Ley Nº 35 de 1914, Sobre establecimientos de castigo. 
Congreso de la República de Colombia. (19 de agosto de 1993). Ley N 65, por la cual se expide el Código Penitenciario y Carcelario.

Congreso de la República de Colombia. (20 de enero de 2014). Ley N 1709, por medio de la cual se reforman algunos artículos de la Ley 65 de 1993, de la Ley 599 de 2000, de la Ley 55 de 1985 y se dictan otras disposiciones.

Corte Interamericana de Derechos Humanos. (18 de septiembre de 2003). Sentencia, Caso Bulacio Vs. Argentina. [MP. Antonio Cancado Trindade].

Corte Interamericana de Derechos Humanos. (22 de noviembre de 2004). Resolución de medidas provisionales respecto de Argentina en el caso de las penitenciarías de Mendoza. [MP. Sergio García Ramírez].

Corte Interamericana de Derechos Humanos. (14 de mayo de 2013). Sentencia, caso Mendoza y otros vs. Argentina. [MP. Diego García-Sayán].

Corte Interamericana de Derechos Humanos. (22 de mayo de 2014). Resolución de medidas provisionales respecto de Brasil en el asunto del complejo penitenciario de Curado. [MP. Humberto Sierra Porto]

Del Pozo, F. y Martínez, J. (2015). Retos del tratamiento penitenciario en Colombia: enfoque y acción diferencial de género desde la perspectiva internacional. Revista Criminalidad, 57(1), 9-25.

Díaz, D. (2017). Procesos de enseñanza-aprendizaje para las personas privadas de libertad a partir de un análisis de Jn 4,1-42. Franciscanum. Revista de las Ciencias del Espíritu, 59(168), 321-354.

Duran, D. (Ed.). (2006). Personas privadas de la libertad, jurisprudencia y doctrina. Bogotá, Colombia: Oficina en Colombia del Alto Comisionado de las Naciones Unidas para los Derechos Humanos. Recuperado de http://www.corteidh.or.cr/tablas/24430.pdf

Echeverry, B. (1971). Temas penitenciarios. Bogotá, Colombia: Publicaciones Escuela Penitenciaria Nacional.

Fabra, J. (2015). Filosofia de la responsabilidad extracontractual: un llamado al debate. Recuperado de: https://archivos.juridicas.unam.mx/www/bjv/libros/8/3876/23.pdf

Foucault, M. (1983). Vigilar y Castigar; nacimiento de la prisión (8 ed.). México: Siglo XXI editores.

Galvis, M. C. (2003). Sistema penitenciario y carcelario en Colombia: Teoría y realidad. Bogotá, Colombia: Pontificia Universidad Javeriana.

Giraldo, J. y Giraldo, O. (2007). Metodología y técnica de la investigación jurídica. Bogotá, Colombia: Librería Ediciones del Profesional Ltda. 
González, L. M. (2010). Reinserción social, un enfoque psicológico. Derecho y Realidad, (16), 267-276.

Gorra, D. (2013). Aproximación al concepto de resocialización en sujetos penalizados mediante redes semánticas. Fundamentos en Humanidades, 14(27), 119-133.

Hernández, H. (2018). El fracaso de la resocialización en Colombia. Revista de Derecho, (49), 1-41.

Howard, J. (Trad. 2003). El estado de las prisiones en Inglaterra y Gales. México: Siglo XXI Editores.

Huertas, O., Trujillo, J. y Silvera, A. (2015). Perspectivas de los derechos humanos y la libertad en contextos de sistemas penitenciarios. Análisis Político, 28(84), 15-134.

Instituto Rosarista de Acción Social Rafael Arenas Ángel. (2011). Desarrollo del sistema penitenciario y carcelario colombiano entre 1995 y 2010. Bogotá, Colombia: Universidad del Rosario.

Jara, L. (2017). Estado garante del derecho a la salud de las personas privadas de la libertad. Diálogos de Saberes, (46), 79-110.

López, M. (2017). La celda como vivienda del interno en centros penitenciarios. Revista Criminalidad, 59(1), 95-103.

Mayorga, N. (2015). Sistema penitenciario y carcelario en Colombia, dentro del marco de un Estado Social de Derecho. Bogotá, Colombia: Universidad Militar Nueva Granada.

Melossi, D. y Pavarini, M. (1980). Cárcel y fábrica. México: Siglo XXI Editores.

Mercado, C. (2014). Cien años de construcción de un sistema carcelario y penitenciario en Colombia. Bogotá, Colombia: Instituto Nacional Penitenciario y Carcelario-INPEC.

Micachán, J. E. y Álvarez Rojas, D. M. (2018). El trabajo penitenciario en Colombia y su impacto en la reinserción social y laboral. Bogotá, Colombia: Universidad de La Salle.

Ministerio de Justicia y del Derecho-Dirección de Política Criminal y Penitenciaria. (2017). Indicadores de derechos humanos en el sistema penitenciario y carcelario. Bogotá, Colombia: Ministerio de Justicia y del Derecho, Corporación Alemana para la Cooperación Internacional.

Núñez, L. (2017). La Ley 1709 de 2014. Bogotá, Colombia: ABECES Jurídico.

Oficina del Alto Comisionado de las Naciones Unidas para los Derechos Humanos. (2004). Los Derechos Humanos y las prisiones "Manual de capacitación en Derechos Humanos para funcionarios de prisiones". Organización de las Naciones Unidas.

Oficina en Colombia del Alto Comisionado de las Naciones Unidas para los Derechos Humanos. (2006). Desde la prisión realidades de las cárceles en Colombia. Organización de las Naciones Unidas para los Derechos Humanos. 
Palacios, G. (2016). Los derechos humanos como límites al sistema carcelario en Colombia. Derecho y Realidad, 14(28), 245-271.

Pedraza, R. (2015). Resocialización y dignidad humana en el sistema penitenciario y carcelario colombiano. Hipótesis Libre, (10), 11-14.

Presidencia de la Republica de Colombia. (7 de julio de 1934). Decreto N 1405, sobre el régimen carcelario y penitenciario.

Presidencia de la Republica de Colombia. (18 de julio de 1960). Decreto N 1716, por el cual se reorganiza el ministerio de justicia.

Presidencia de la Republica de Colombia. (17 de julio de 1964). Decreto N 1817, por el cual se reforma y adiciona el Decreto 1045 de 1934.

Presidencia de la República. (12 de enero de 2017). Decreto 040, por el cual se adiciona un nuevo Capítulo al Título 1 de la Parte 2 del Libro 2 del Decreto 1069 de 2015, Decreto Único Reglamentario del Sector Justicia y del Derecho, y se reglamentan los Centros Especiales de Reclusión a que se refieren los artículos 23 A, 24 y 25 de la Ley 65 de 1993 modificados por los artículos 15, 16 y 17 de la Ley 1709 de 2014.

Quintero, F. (2011). Tratamiento penitenciario en la provincia de Buenos Aires: El desafio de ajustar la legislación a la práctica internacional. Revista Opinión Jurídica, 10(19), 171-178.

Raso, G. y Leone, D. (2016). La violación de derechos humanos en el ámbito carcelario. Recuperado de http://www.biblioteca.unlpam.edu.ar/rdata/tesis/e_rasvio716.pdf

República de Colombia. (1991). Constitución política de Colombia. Gaceta Constitucional No. 116 de 20 de julio de 1991.

Ríos, L. (2016) Política penitenciaria, cumplimiento de los fines de la pena y los derechos humanos: El caso de la estructura Tres Delcomeb. Bogotá, Colombia: Universidad Santo Tomás.

Ruiz, M. (2007). Primera aproximación hacia una pedagogía de la resocialización. Nómadas. Critical Journal of Social and Juridical Sciences, 16(2).

Ruiz-Pérez, J., Malaver-Pérez, I., Romero, P., López, E. y Silva, M. (2018). Representaciones sociales del tratamiento penitenciario en población reclusa y en servidores penitenciarios. Psychologia, 12(1), 115-132. doi: 10.21500/19002386.2986

Sampieri, R, Fernández, C y Baptista, M. (2014). Metodología de la investigación. México: Mc Graw Hill.

Secretaría General de la Organización de Estados Americanos. (11 de febrero de 1978). Convención Americana sobre Derechos Humanos (Pacto de San José de Costa Rica). Gaceta Oficial, (9460). Recuperado de https://www.oas.org/dil/esp/1969_Convenci\%C3\%B3n_Americana_sobre_Derechos_Humanos.pdf 